\title{
ADITIVOS ALIMENTARES E SUAS REAÇÕES ADVERSAS NO CONSUMO INFANTIL
}

Fabrícia de Souza FERREIRA*

*Nutricionista Graduada pela Universidade Federal da Paraíba, fabriciasouzaferreira@ gmail.com.

Recebido em: 11/11/2014 - Aprovado em: 16/06/2015 - Disponibilizado em: 15/07/2015

\begin{abstract}
RESUMO: Gradativamente os hábitos alimentares da população vêm sofrendo modificações e estão sendo substituídos por produtos industrializados devido a sua praticidade, melhor sabor e maior durabilidade adquirida através do emprego de aditivos alimentares. É evidente a importância dos aditivos sob o ponto de vista tecnológico, porém, é necessário estar prudente aos possíveis riscos toxicológicos que podem ser ocasionados pela ingestão comumente dessas substâncias principalmente pelo público infantil. Este trabalho objetivou reunir informações sobre os aditivos e seus efeitos adversos através de resgates na literatura em uma revisão sistemática. Trata-se de um estudo exploratório descritivo que utilizou como instrumento de pesquisa as bases de dados LILACS e MEDLINE e a biblioteca eletrônica SciELO. Foi observada nos estudos que os corantes são os aditivos que apresentaram maiores reações adversas na literatura, induzindo danos ao DNA, possibilitando o surgimento ne neoplasias em várias regiões do corpo, além disso, podem acarretar reações alérgicas, choques anafiláticos, e transtornos no sistema nervoso central de crianças causando hiperatividades, dificuldade de aprendizagem e irritabilidades. Nitritos e Nitratos (conservantes) são fortes desencadeadores de neoplasias, principalmente de estômago, além de impedir o transporte normal de oxigênio, podendo ser letal para pessoas sensíveis e crianças em altas doses. Alguns antioxidantes, também foram relacionados ao aparecimento de câncer e vários outros aditivos foram citados como causadores de reações adversas. É necessária a criação de estratégias para a redução do consumo dessas substâncias toxicas para que problemas maiores sejam evitados.
\end{abstract}

Palavras-Chave: Toxicidade. Alimentos industrializados. Corantes. Hábitos Alimentares. Neoplasias.

\begin{abstract}
Increasingly eating habits of the population have been modified and are being replaced by industrial products due to its convenience, better taste and greater durability gained through the use of food additives. Clearly the importance of additives in the technological point of view, however, one must be cautious of possible toxicological risks that may be caused by ingestion of these substances commonly mainly by children. This study aimed to gather information about the additives and their adverse effects through redemptions in the literature in a systematic review. This is an exploratory descriptive study used as a research tool the LILACS and MEDLINE and SciELO electronic library. Was observed in studies that the dyes are additives that showed greater adverse reactions in the literature, inducing DNA damage, allowing the n neoplasms arising in various regions of the body, moreover, may cause allergic reactions, anaphylactic shock, and damage to the nervous system central children causing hyperactivity, learning difficulties and irritabilidades. Nitrates and nitrites (preservatives) are strong triggering of neoplasias, especially stomach, and prevent normal oxygen delivery, and may be lethal to susceptible children and people at high doses. Some antioxidants, were also related to the onset of cancer and various other additives were cited as causing adverse reactions. Creating strategies to reduce the consumption of these toxic substances to major problems are avoided is required.
\end{abstract}

Keywords: Toxicity. Processed foods. Dyes. Food Habits. Neoplasms.

\section{INTRODUÇÃO}

Devido à necessidade crescente de

alimentos com maior durabilidade e
praticidade no consumo, os hábitos
alimentares vem sofrendo grandes
modificações ao longo do tempo onde
alimentos in natura estão sendo

gradativamente substituídos por alimentos industrializados. Esse fato tem gerado questionamentos e preocupações quanto à segurança do emprego de aditivos alimentares (DALL'AGNOL et al., 2013; POLÔNIO; PERES, 2009).

A avaliação dos aditivos alimentares no âmbito mundial é respaldada no controle 
da IDA (Ingestão Diária Aceitável), desenvolvida pelo Joint FAO/WHO Expert Committee on Food Additives (JECFA). No Brasil, elaborações e publicações da legislação que dispõe sobre o uso de aditivos competem a Agência Nacional de Vigilância Sanitária (ANVISA) que, por sua vez, define aditivos como qualquer substância intencionalmente adicionado aos alimentos sem o desígnio de nutrir objetivando modificar as características dos alimentos e aumentar sua vida útil (BRASIL, 1997).

É evidente a importância dos aditivos sob o ponto de vista tecnológico na produção de alimentos. Porém, é necessário estar atento aos possíveis riscos toxicológicos que podem ser acarretados pela ingestão frequente dessas substâncias (POLÔNIO, 2010).

Distintas pesquisas têm mostrado reações tóxicas incididas pelos aditivos, quer seja aguda ou crônica, que desencadearam processos alérgicos, alterações neurocomportamentais e, em longo prazo, neoplasias (DI LORENZO et al., 2002; GUIMARÃES 2010; MOUTINHO; BERTGES; ASSIS, 2007).

Nesse sentido, ressalta-se que as crianças, principalmente os lactentes, exibem maior suscetibilidade às reações atribuladas provocadas pelos aditivos alimentares que os adultos. Isto ocorre devido à quantidade ingerida, em relação à massa corporal, ser maior na criança. Além disso, os lactentes apresentam imaturidade fisiológica, não sendo capazes de metabolizar e nem excretar essas substâncias adequadamente acarretando o desencadeamento das reações adversas (POLÔNIO, 2010; POLÔNIO; PERES, 2009; SCHUMANN; POLÔNIO; GONÇALVES, 2008).

A FAO/WHO (1995) indica que não sejam empregados aditivos intencionais em alimentos designados a crianças menores de um ano, como rege o Codex Alimentarius. Apesar disso, no mercado existem inúmeros produtos ricos em aditivos que são consumidos tanto por criança como por adultos, incluindo os lactentes menores de um ano, tornando-os mais vulneráveis ao desencadeamento de processos toxicológico (FAO/WHO, 1995 apud POLÔNIO, 2010).

Diante do exposto, este trabalho objetiva reunir informações sobre os aditivos e seus efeitos adversos através de resgates na literatura em uma revisão sistemática.

\section{METODOLOGIA}

Estudo exploratório descritivo que utilizou como instrumento de pesquisa as bases de dados LILACS e MEDLINE e a biblioteca eletrônica SciELO com finalidade de reunir trabalhos científicos que abordassem o tema referente. A busca foi realizada tendo como termo indexador "aditivos alimentares", "aditivos toxicológicos" e "aditivos no consumo infantil". 


\section{DESENVOLVIMENTO}

\section{CORANTES}

Os corantes alimentares, substâncias que possuem o atributo de conceder ou intensificar a coloração de alimentos, são considerados os aditivos mais genotoxicos existentes, principalmente os pertencentes ao grupo "Azo", um derivado nitroso capaz de ocasionar reações de hipersensibilidade e tem sido foco de estudos de mutagênese e carcinogênese por produzir, após ser metabolizado pela microflora intestinal, amina aromática e ácido sulfanílico, compostos com alto potencial cancerígenos (MOUTINHO, BERTGES; ASSIS, 2007; FREITAS, 2012). Os corantes mais usados e que fazem parte desse grupo são a tartrazina, amarelo crepúsculo, vermelho ponceau R4, amarato, azorrupina e vermelho 40, encontrados em alimentos como sucos artificiais, sorvetes, balas, gelatinas, iogurtes, refrigerantes e outros produtos coloridos artificialmente (GOMES, 2012).

Entre os corantes "azo", a tartrazina tem o maior respaldo sendo relacionada com diversas reações de hipersensibilidade como urticária, asma, náusea, anafilaxia, vômitos, dermatite, dor de cabeça, eczema, angioedema, bronquite, renite e broncoespasmos. Em doses elevadas induz à lesão no DNA em estômago, cólon e bexiga urinária possibilitando o surgimento de câncer em longo prazo (ANVISA, 2007; FREITAS, 2012). Além disso, pode desencadear hipercinesia, distúrbios de comportamento, e eosinofilia (POLÔNIO, 2010). Em casos raros, a tartrazina pode inibir a agregação plaquetária interferindo na coagulação sanguínea (PRADO; GODOY, 2003).

Uma grande parcela da população mundial apresenta alguma reação adversa à tartrazina, principalmente quando ingerida precocemente antes de um ano de idade. Em alguns países da Europa a tartrazina foi proibida devido aos seus efeitos deletérios, porém no Brasil esse é um dos corantes mais aplicados em alimentos, estando presentes na maioria dos produtos industrializados (DALL'AGNOL et al., 2013).

É importante atentar-se para alimentos que são comercializados sem a devida rotulagem como sobremesas, sorvetes e produtos de confeitaria que contém tartrazina em sua composição e que são muito consumidos pelo público infantil. A ingestão desses produtos pode desencadear grandes riscos, induzindo ao consumo acima do aceitável da IDA que deveria ser de até 7,5 $\mathrm{mg} / \mathrm{Kg} / \mathrm{dia}$ de peso (ANVISA, 2007; POLÔNIO; PERES, 2009).

Uma pesquisa que analisou a concentração de tartrazina em alimentos consumidos por crianças e adolescentes observou uma média significativa em grande parte dos alimentos industrializados comuns entre essa faixa etária e, observou também que as quantidades de tartrazina encontrada em sucos em pó e pó para gelatina 
encontravam acima dos valores preconizados pela legislação (PIASINI et al., 2014).

Além da tartrazina, os corantes: amaranto, vermelho ponceau $4 \mathrm{R}$, eritrosina e verde brilhante acarretam reações adversas de hipersensibilidade. $\mathrm{O}$ corante amarelo crepúsculo pode desencadear reações ocasionando angioedema, vasculite, púrpura e choque anafilático (FREITAS, 2012; POLÔNIO, 2010).

Um estudo que avaliou a presença de corantes em alimentos consumidos por préescolares mostrou que os iogurtes eram os alimentos mais consumidos e que grande parte dos iogurtes apresentaram corantes em sua composição, sendo que $47 \%$ apresentou o corante vermelho ponceau $\mathrm{R} 4 ; 10,5 \%$ o amarelo crepúsculo e $5,2 \%$ a tartrazina. (FREITAS, 2012).

Desde tempos antigos, pesquisas tem indicado uma ligação entre o consumo de determinados corantes alimentares como: tartrazina, amaranto, vermelho ponceau 4R, eritrosina e caramelo amoniacal e o surgimento da hiperatividade em crianças (BORIS; MANDEL, 1994; MCCANN et al., 2007). Crianças hiperativas apresentam hipercinesia, irritabilidade, impulsividade, déficit de atenção, consequentemente, dificuldade de aprendizagem e excesso de distração. Quando não corretamente assistidas, ficam propensas a desenvolverem distúrbios comportamentais, emocionais e sociais além de levarem o transtorno para a vida adulta (GUIMARÃES, 2010; SOUZA; FRIGHETTO; SANTOS, 2013).

\section{CONSERVANTES}

Os conservantes são considerados substâncias adicionadas aos alimentos com o propósito de evitar ou retardar alterações provocadas por microrganismos ou enzimas e assim, aumentar a vida útil dos mesmos (LIMA, 2011; POLÔNIO, 2010). Os que mais apresentam reações adversas na literatura são os nitritos, nitratos e sulfitos (BARRETTO; SILVA, 2006; PEREIRA; MOURA; CONSTANT, 2008; SEMEDO, 2009).

Nitritos e nitratos são conservantes atuantes contra o aparecimento da bactéria Clostridium botulinum, sendo muito utilizado na produção de embutidos cárneos. Os nitritos, além de conservarem a carne são fixadores de cor e agentes de cura (ANDRADE, 2013; ANDRADE; TRIGUEIRO, 2008; SEMEDO, 2009).

$\mathrm{O}$ nitrito é bem mais tóxico que o nitrato, porém o nitrato se reduz a nitrito na corrente sanguínea (ANDRADE, 2013; CÂMARA, 2006). A principal apreensão do uso desses conservantes é decorrente dos vastos efeitos tóxicos provocados. O nitrito pode gerar a nitrosamia, um composto de ação altamente carcinogênica responsável pelo desencadeamento de neoplasias, principalmente gastrointestinais. Além disso, o nitrito pode agir sobre a hemoglobina, oxidando o ferro, do estado ferroso ao férrico, produzindo a metamioglobina e impedindo a 
função normal do transporte de oxigênio (BARRETTO; SILVA, 2006; CÂMARA, 2006; FIGUEIRÓ, 2013; POLÔNIO, 2010; SEMEDO, 2009).

Segundo Nascimento (2010), esse aditivo é comumente relacionado ao aumento da pressão arterial e a doenças cardíacas. Possuem ação vasodilatadora que ocasionam relaxamento da musculatura lisa em geral, além de desconforto gastrointestinal, enrubescimento da face e extremidades e dor de cabeça. Em doses mais elevadas podem ser toxicas causando cianose, anafilaxia, náusea, tonturas, fraqueza vômitos, dores abdominais, colapso, asma, angioedema e gastrite. Em longo prazo pode desencadear doenças do aparelho circulatório e tumores específicos como de estômago, esôfago, cólon, reto, mama e ovário (FIGUEIRÓ, 2013; NASCIMENTO, 2010; OLIVEIRA; ARAÚJO; BORGO, 2005; POLÔNIO, 2010).

O comitê FAO/WHO, diante destes riscos graves, estabeleceu para nitrito uma IDA de 0-0,06 mg/kg/dia de peso corpóreo e para nitrato, IDA de $0-3,7 \mathrm{mg} / \mathrm{kg} /$ dia de peso corporal e proibiu terminantemente $\mathbf{o}$ emprego de nitrito em alimentos infantis para crianças menores de três meses. Lactentes nessa idade podem até morrer com a ingestão inadequada de nitratos e nitritos devido à imaturidade fisiológica das mesmas (CÂMARA, 2006, SEMEDO, 2009).

Os sulfitos, que incluem o dióxido de enxofre e seus sais de sódio, potássio e cálcio, são aditivos conservadores de ação antimicrobiana seletiva, inibindo o crescimento de bactérias e leveduras. Eles também são utilizados como agentes antioxidantes inibindo parcialmente o escurecimento enzimático e o não enzimático. São muito aplicados em produtos como sucos industrializados, frutas secas, frutos do mar, alimentos em conserva, bebidas gaseificadas e alcoólicas. Apresentam uma IDA de 0,7 $\mathrm{mg} / \mathrm{kg}$ expressa como dióxido de enxofre (SO2) (MONTES, 2013; POLÔNIO, 2010).

A ingestão desse aditivo tem sido relacionada a reações adversas em lactentes e pessoas sensíveis, principalmente, os asmáticos, como broncoespasmos, anafilaxia, urticária, angioedema, hipotensão, náusea, irritação gástrica local pela formação de ácido sulforoso, dores de cabeça, distúrbio do comportamento e hiperatividade em crianças, erupções cutâneas, diarreia e crise asmática. A maioria das reações de intolerância adota a forma de ataques asmáticos e urticária (COELHO， 2008; FAVERO; RIBEIRO; AQUINO, 2011; MACHADO; TOLEDO; VICENTE, 2006). Também apresenta ação carcinogênica (MONTES, 2013).

Dependendo da sensibilidade do indivíduo, reações adversas podem ser induzidas pela ingestão de 2 a $250 \mathrm{mg}$, por esta razão, os alimentos que possuem sulfitos em sua composição deve obrigatoriamente indicar a presença do mesmo em seu rótulo (MACHADO; TOLEDO; VICENTE, 2006). 
O sulfito é convertido em sulfato através da enzima sulfito oxidase, evitando no organismo reações toxicas, uma vez que o sulfato é inócuo e rapidamente excretado. Lactentes e pessoas que apresentem atividade reduzida da enzima sulfito oxidase podem apresentar graves distúrbios neurológicos causados por reações toxicas através do acúmulo de sulfito no organismo (FAVERO; RIBEIRO; AQUINO, 2011; MONTES, 2013).

\section{ANTIOXIDANTE}

A atividade antioxidante é a capacidade de um composto inibir a degradação oxidativa. Os antioxidantes sintéticos são usados como aditivos alimentares para prevenir ou retardar a oxidação lipídica (HONORATO et al., 2013). Destes, os mais utilizados pelas industrias brasileiras são o butil-hidroxitolueno (BHT), butil-hodroxianisol (BHA), butilhidroquinona (TBHQ) e o galato de propila (TAKEMOTO; FILHO; GODOY, 2009).

$\mathrm{O}$ uso do BHT e BHA tem gerado grandes polêmicas, uma vez que esses aditivos são genotoxicos capazes de originar lesões aos genes de uma célula ou de um organismo. Esses antioxidantes são comumente encontrados em alimentos ricos em óleos e gorduras, consumidos por todas as faixas etárias, como biscoitos, margarina, manteiga, salgadinhos de pacote, bolos, carnes, batata frita e cereais. A IDA permitida pelo JECFA e pela legislação brasileira é de
$0-0,5 \mathrm{mg} / \mathrm{kg}$ de peso corporal (ALBUQUERQUE et al., 2012; POLÔNIO, 2010; TOLEDO;CAMPOS, 2000).

Estudos experimentais em animais mostraram que em doses elevadas o BHT pode desencadear problemas hepáticos, gastrointestinais e ativar o aparecimento de tumores. Já o BHA estimula o aumento da excreção urinária de ácido ascórbico, retardo de crescimento infantil e elevação da mortalidade perinatal (LEDEVER, 1991 apud ALBUQUERQUE et al., 2012).

O BHA e BHT são considerados fatores de risco para o transtorno do déficit de atenção e hiperatividade em crianças e induz danos no DNA do estomago, cólon, bexiga e cérebro causando neoplasias em longo prazo (POLÔNIO, 2010).

\section{REALÇADOR DE SABOR}

O glutamato monossódico (GM) é um aditivo utilizado nas indústrias como flavorizantes (CARVALHO et al., 2011). No Brasil, a ANVISA permite o uso do GM em quantidades suficientes em produtos como molhos, carnes, caldos de carne, macarrão instantâneo, sopas, sucos e outros produtos, não existindo limites máximos permitidos (BRASIL, 2001).

O glutamato é uma excito-toxina, ou seja, ele superexcita as células causando danos em vários graus. Em altas doses o GM pode ser tóxico ao sistema nervoso central, podendo resultar em uma alteração aguda do núcleo arqueado do hipotálamo, ocasionando 
diversos distúrbios como disfunção sexual, obesidade, diabetes, distúrbios de comportamento como aparecimento de hiperatividade, autismo e transtorno de déficit de atenção e déficit de desenvolvimento. Em longo prazo, pode desenvolver distúrbios mais sérios como Mal de Alzheimer, Mal de Parkinson e Mal de Lou Gehrig (HOCAYEN, 2012; CARVALHO et al., 2011). Em crianças, quando ingerido com o estômago vazio, esse aditivo pode ocasionar sintomas como cefaleia, irritabilidade, dores estomacais, calafrios, agitação e delírios (BARRETTO; SILVA, 2006). Não é indicado o uso desse aditivo em lactentes devido à imaturidade cognitiva dos mesmos (BARRETTO; SILVA，2006; CARVALHO et al., 2011).

\section{AROMATIZANTES}

De acordo com a Resolução RDC $n^{\circ} .2$ de 15 de janeiro de 2007 da ANVISA, que aprova o Regulamento Técnico sobre Aditivos Aromatizantes, os aromas podem ser classificados como aromatizantes naturais e artificiais, os naturais tem como matéria prima produtos retirados da natureza de origem animal ou vegetal e os artificiais são produzidos através de processos químicos.

Não foi encontrado na literatura relatos de toxicidades nos aromatizantes naturais, porém doses elevadas de aromatizantes sintéticos foram relacionados a reações de irritabilidade e narcóticas podendo trazer problemas de retardo de crescimento infantil e câncer quando há uma exposição excessiva e prolongada dessas substâncias (SALINAS, 2002)

\section{CONSIDERAÇÕES FINAIS}

Com a globalização e o avanço da tecnologia houve concomitantemente modificação dos hábitos alimentares da população que tem substituído gradativamente os alimentos in natura por um padrão alimentar ocidentalizado composto por alimentos industrializados ricos nos mais diversos tipos de aditivos. Cada dia mais os aditivos estão sendo inseridos na alimentação precocemente de forma assoberbada, trazendo sérios problemas de saúde de curto e longo prazo, principalmente para crianças que são os maiores consumidores desses produtos. Faz-se necessária a participação ativa dos órgãos de regulação na vigilância e controle desses produtos.

É necessária a criação de estratégias para a redução do consumo dessas substâncias toxicas e a criação de hábitos alimentares saudáveis para que problemas maiores sejam evitados.

\section{REFERÊNCIAS}

ALBUQUERQUE, M.V et al. Educação

Alimentar: Uma Proposta de Redução do Consumo de Aditivos Alimentares. Química

Nova na Escola. [S.I], v. 34, n. 2, p. 51-57, Maio 2012; 
ANDRADE, L.L; TRIGUEIRO, I.N.S. Nitrito

residual em salsicha de ave comercializadas

em Salvador -BA/ Residual nitrite in

sausages bird marketed in Salvador-BA.

Higiene Alimentar, [Salvador], v. 22, n. 166/167, p. 185-188, nov./dez. 2008;

\section{ANDRADE, M. P. D. Efeito da radiação} gama e nitrito na inibição do Clostridium botulinum e na qualidade de mortadelas. 2013. 155f. Tese (Doutorado em Ciência dos Alimentos) - Universidade Federal de Lavras, Lavras, 2013;

ANVISA. Informe técnico: Considerações sobre o corante amarelo tartrazina, 2007.

Disponível em: http://www.anvisa.gov.br/alimentos/informes/ 30_240707.htm. Acesso em: 25 jan. 2014;

BARRETTO, J.R; SILVA, L.R. Intoxicações

Alimentares. In: Pronto Atendimento em

Pediatria $2^{a}$ Edição, Bahia: Guanabara

Koogan, 2006;

BORIS, M; MANDEL, F.S. Foods and additives are common causes of attention deficit hyperactivity disorder in children. Ann Allergy, [S.I], v. 72 n.1 p. 462-468, 1994;

BRASIL. Agência Nacional de Vigilância Sanitária. Sistema Internacional de Numeração de Aditivos Alimentares.

Brasília, 2001. Disponível em: <http://www.anvisa.gov.br/

alimentos/aditivo.htm> Acesso em: $29 \mathrm{dez}$. 2013;

BRASIL. Portaria n ${ }^{\circ} 540$ - SVS/MS, de 27 outubro 1997. Aprova o regulamento técnico: aditivos alimentares - definições, classificação e emprego. Diário Oficial da União, Brasília, 28 out. 1997;

\section{CÂMARA, S.A.V. Fatores de Risco para}

Câncer de Estômago: Avaliação dos Teores de Nitrato e Nitrito em Linguiças. 2006. 106f. Dissertação (Mestrado em Saúde Coletiva), Universidade Federal de Mato Grosso do Sul, Campo Grande, 2006;

CARVALHO, P.R.R.M. et al. Características e Segurança do Glutamato Monossódico como Aditivo Alimentar: Artigo de Revisão. Visão Acadêmica, Curitiba, v. 12, n. 01, p. 53-60, Jan./Jun. 2011;

\section{COELHO, S.F.L. Efeito de diferentes} concentrações de conservantes alimentícios no crescimento in vitro de fungos termorresistentes e bactérias patogênicas. 2008. 79f. Dissertação (Mestrado em Nutrição)- Faculdade de Nutrição, Universidade Federal de Alagoas, Maceió, 2008;

DALL'AGNOL, R. P. A Utilização De Corantes Artificiais Em Produtos 
Alimentícios No Brasil/ The Utilization Of

Artificial Colorings In Alimentary Products In

Brazil. In: Simpósio Internacional de

Inovação Tecnológica, 4., 2013, Aracaju.

Anais... Aracajú: SIMTEC, 2013. p. 26-37;

DI LORENZO, G. et al. Urinary metabolites of histamine and leukotrienes before and after placebo-controlled challenge with ASA and food additives in chronic urticarial patients. Allergy, [S.I.], n. 57, v. 12, p. 1180-1186, 2002;

FAVERO; D.M; RIBEIRO, C.S.G; AQUINO, A.D. Sulfitos importância na indústria alimentícia e seus possíveis malefícios à população. Segurança Alimentar e Nutricional, Campinas, v. 18, n. 1, p. 11-20, 2011;

FREITAS, A. S. Tartrazina: uma revisão das propriedades e análises de quantificação. Acta Tecnológica. v. 7, n. 2, p. 65-72, 2012;

GOMES, L. M. M. Inclusão de

Carotenoides de Pimentão Vermelho em

Ciclodextrinas e Avaliação da Sua

Estabilidade, Visando Aplicação Em

Alimentos. 2012. 108p. Dissertação (Mestre em Ciências Aplicadas), Faculdade de Farmácia, Universidade Federal Fluminense, Niterói, 2012;
GUIMARÃES, N.M.C.P. Perturbação de

Hiperatividade e Défice de Atenção - para além da genética. 2010. 31f. Dissertação (Mestrado Integrado em Medicina), Instituto de Ciências Biomédicas Abel Salazar Universidade do Porto, Porto, 2010;

HOCAYEN, P.A.S. Efeito da administração oral do extrato de Baccharis dracunculifolia na obesidade induzida por glutamato monossódico (MSG), 2012. 108f.

Dissertação (Mestrado em Ciências

Biológicas) - Universidade Estadual de Ponta Grossa, Universidade Estadual do Centro Oeste, Ponta Grossa, 2012;

HONORATO, T.C. et al. Aditivos

Alimentares: Aplicações e Toxicologia.

Revista Verde, Mossoró, v. 8, n. 5, p.01 -11, (Edição Especial) dezembro, 2013;

LIMA, G.F. Aditivos Alimentares:

Definições, Tecnologia E Reações Adversas. VEREDAS FAVIP, v. 4, n. 2, p. 101-107, jul./dez. 2011;

MACHADO, R.M.D; TOLEDO,M.C.F; VICENTE,E. Sulfitos em alimentos. Braz.J. Food Technol. (ITAL), Campinas, v.9, n.4, p.265-275, out./dez. 2006;

MCCANN, D. et al. Food additives and hyperactive behavior in 3-year-old and 8/9year-old children in the community: a 
randomized, double-blinded, placebo-

controlled trial. Lancet [S.I], v. 370, n. 1, p.

1560-1567, 2007;

MONTES, R.H.O. Estudo e aplicação de eletrodo modificado com hexacianoferrato de óxido de rutênio para a deteç̧ão seletiva de sulfito. 2013.93 f. Dissertação

(Mestrado)-Universidade Federal de Uberlândia, Uberlândia, 2013;

MOUTINHO, I.L.S; BERTGES, L.C; ASSIS, R.V.C. Prolonged use of Food Dye Tartrazine and its Effects on the Gastric Mucosa of Wistar Rats. Braz.J. Biol., [S.I], v. 67, n. 1, p. 141-145, 2007;

PEREIRA, A. C. S.; MOURA, S. M.;

CONSTANT, P. B. L. Alergia alimentar: sistema imunológico e principais alimentos envolvidos. Semina: Ciências Biológicas e da Saúde, Londrina, v. 29, n. 2, p. 189-200, jul./dez. 2008;

POLÔNIO, M. L. T. Percepção de mães quanto aos riscos à saúde de seus filhos em relação ao consumo de aditivos

alimentares: o caso dos pré-escolares do Município de Mesquita. 2010. 129f. Tese (Doutorado em Ciências na área de Saúde Pública e Meio Ambiente). Escola Nacional de Saúde Pública Sergio Arouca, Rio de Janeiro, 2010;
POLÔNIO, M.L.T; PERES, F. Consumo de aditivos alimentares e efeitos à saúde: desafios para a saúde pública brasileira. Cad. Saúde Pública, Rio de Janeiro, v. 25, n. 8, p.1653-1666, ago. 2009;

PIASINI, A. et al. Análise da Concentração de Tartrazina em Alimentos Consumidos por Crianças e Adolescentes. Revista Uningá, Lajeado, v.19, n.1, pp.14-18, Jul/Set 2014;

PRADO, M.A; GODOY, H.T. Corantes artificiais em alimentos. Alim. Nutr., Araraquara, v.14, n. 2, p. 237-250, 2003;

SALINAS, R.D. Alimentos e Nutrição: Introdução à Bromatologia. $3^{\mathrm{a} E d}$. Porto Alegre: Artmed, 2002;

SCHUMANN, S.P.A; POLÔNIO,M.L.T. GONÇALVES, A. Avaliação do consumo de corantes artificiais por lactentes, pré-escolares e escolares. Ciênc. Tecnol. Aliment., Campinas, v. 28, n. 3, p. 534-539, jul./set. 2008;

\section{SEMEDO, J. Aditivos Alimentares em Cabo}

Verde. 2009. 57f. Monografia (Licenciatura em Ensino da Química), Departamento de Ciências e Tecnologia - Universidade de Cabo Verde, Cabo Verde, 2009; 
SOUZA, V.M.F; FRIGHETTO, A.M;

SANTOS, J.C. Refletindo Sobre

Transtorno de Déficit de Atenção e

Hiperatividade na Educação Infantil e

Séries Iniciais. Rev. de Ciências Sociais

Do Norte De Mato Grosso. [S.I], v. 1, n.

2, p. 01-14, 2013;

TAKEMOTO, E.; FILHO, J.T.; GODOY,

H.T. Validação de metodologia para a

determinação simultânea dos antioxidantes

sintéticos em óleos vegetais, margarinas e

gorduras hidrogenadas por clae/uv. Revista

Química Nova, [S.I], v.32, n., p.1189-1194,

2009.

TOLEDO, M.C.F; CAMPOS, G.C.M.

Determinação de BHA, BHT e TBHQ em

Óleos e Gorduras por Cromatografia Líquida de Alta Eficiência. Brazilian Journal Food

Technology, [S.I], v. 3, n.1, p. 65-71, 2000; 